\title{
ENTRE MEMÓRIAS E MÁSCARAS: UMA LEITURA DA CHINA CONTEMPORÂNEA NO ROMANCE DISTÓPICO OS ANOS DE FARTURA, DE CHAN KOONCHUNG ${ }^{1}$
}

\author{
Camila Araújo Gomes ${ }^{2}$ \\ Rachel Esteves Lima ${ }^{3}$
}

\begin{abstract}
Resumo: Censurado na República Popular da China, o romance distópico $O s$ anos de fartura (2009), do autor chinês Chan Koonchung, apresenta críticas pungentes ao acelerado e, às vezes, contraditório processo de modernização socialista, instalado no país continental desde 1949. A fim de compreender como a nação chinesa é imaginada por Koonchung, o artigo objetiva analisar uma China ficcional relativamente futurista, ambientada no ano de 2013, na condição (aparente) de um país próspero e harmônico, cuja imagem otimista consolidou-se depois da ocorrência do "tsunami financeiro de 2008" que, exclusivamente, arrastara os países capitalistas liderados pelos Estados Unidos da América do Norte para uma grande crise. A investigação visa, também, debruçar-se sobre algumas questões geopolíticas sobre a China, cujo sistema político e econômico é pragmaticamente rotulado, pelo PCC, como "socialismo com características chinesas" e, por vozes discordantes ao Partido, como uma autocracia socialista, concepções que nutrem politicamente a discussão presente nas entrelinhas da ficção científica mencionada. Nesse sentido, o romance tensiona a qualidade democrática da China atual, fazendo menção aos desafios geopolíticos que interferem no crescimento econômico do país. Seria, então, a China na contemporaneidade, uma China do passado? Essa é a pergunta crucial que ecoa na mente dos leitores de $O s$ anos de fartura e que este trabalho pretende discutir.
\end{abstract}

Palavras-Chave: China. Literatura chinesa. Modernização socialista.

\footnotetext{
${ }^{1}$ Este trabalho é resultado da orientação da pesquisa de Iniciação Científica de Camila Araújo Gomes por Rachel Esteves Lima e foi realizado no âmbito do projeto "Modernidades alternativas: a literatura do BRICS na era da globalização", financiado pelo CNPq (Processo 308999/2015-0).

2 Mestranda no Programa de Pós-Graduação de Literatura e Cultura, pela Universidade Federal da Bahia (UFBA).E-mail:mila_araujo25@hotmail.com.

3 Professora do Programa de Pós-Graduação em Literatura e Cultura, pela Universidade Federal da Bahia e pesquisadora do CNPq. E-mail: rachellima@uol.com.br.
} 


\title{
BETWEEN MEMORIES AND MASKS: A READING OF CONTEMPORARY CHINA IN CHAN KOONCHUNG'S DYSTOPIAN NOVEL OS ANOS DE FARTURA
}

\begin{abstract}
Censored in the People's Republic of China, Chan Koonchung's dystopian novel Os anos de fartura (2009) presents a critical view of the accelerated and contradictory process of socialist modernization, installed in mainland China since 1949. The article aims to analyze a fictional China, relatively futuristic, set in 2013, in the (apparent) condition of a prosperous and harmonious country, whose optimistic image occurred after the event of the "financial tsunami of 2008". This crisis had exclusively dragged the capitalist countries led by the United States of America. The investigation also proposes to address some geopolitical issues linked to China, whose political and economic system is pragmatically called, by the Chinese Communist Party (CCP), "socialism with Chinese characteristics". On the other hand, the political opponents of the Party refer to it as a socialist autocracy. This antagonism nourishes the discussion developed between the lines of the mentioned science fiction. In this perspective, the novel highlights the democratic quality of today's China, considering the geopolitical challenges which interfere in the country's economic growth. Is contemporary China, then, a China of the past? This is the crucial question that echoes in the minds of the readers and which this paper intends to discuss.
\end{abstract}

Keywords: China. Chinese Literature. Socialist Modernization.

\section{Memórias em jogo}

Afinal, qual é o "verdadeiro rosto da China 4 ", na contemporaneidade? De início, pode-se dizer que essa é a pergunta que o autor chinês Chan Koonchung tenta responder, apresentando ao longo do enredo de seu romance distópico Os anos de fartura traços políticos, econômicos e culturais que se inscrevem em alto-relevo, consubstanciando negativamente uma imagem nacional da China, país que supreendentemente alcançou, no começo do século XXI, as posições de maior economia regional do Leste asiático e de segunda potência mundial. Operando como um dispositivo literário, a metáfora criada por Koonchung na primeira parte do livro traz à

${ }^{4}$ KOONCHUNG, 2014, p. 42. Essa metáfora foi retirada de um trecho do romance. 
luz uma discussão contemporânea sobre o(s) estilo(s) pelo(s) qual(is) a China é politicamente imaginada (ANDERSON, 2008, p. 33).

Desde 1949, o Partido Comunista Chinês (PCC) governa, de forma centralizada, a China continental. Esse fato histórico sugere que os dirigentes dessa cúpula partidária modelam, adaptam e transformam as memórias (oficiais, coletivas e individuais) que dinamizam o imaginário social da e sobre a nação chinesa. Nesse sentido, pensar o "verdadeiro rosto da China" é, dentre outros aspectos, analisar um jogo político de memórias, constituído "no campo de batalha onde o presente se debate com o passado como um modo de construir o futuro" (ACHUGAR, 2006, p. 181).

Criada por Chan Koonchung em Os anos de fartura, a China ficcional, relativamente futurista, ambienta-se em 2013, na condição (aparente) de um país próspero e harmônico. Essa imagem otimista consolidou-se depois da ocorrência da crise financeira de 2008, que devastara exclusivamente os países capitalistas liderados pelos Estados Unidos da América do Norte. Como o título do romance pressupõe, os anos de fartura na China instauraram-se

depois do tsunami financeiro de 2008, [quando] os países capitalistas liderados pelos Estados Unidos começaram a implodir e só tiveram uns poucos anos de recuperação modesta antes de afundar mais uma vez na estagflação. A nova crise se alastrou mundo afora e nenhum país ficou incólume. E ninguém sabe quando a depressão vai acabar. Apenas a China conseguiu se reerguer e avançar enquanto os outros sucumbem. E agora a economia está aquecida outra vez. Com a demanda interna compensando o parco mercado de exportações e o capital do estado substituindo os investimentos estrangeiros que evaporaram, a previsão atual é de que esse seja o terceiro ano consecutivo em que a economia cresce mais de $15 \%$. A China não apenas mudou as regras do jogo econômico internacional, mas também mudou a natureza da economia ocidental. E, o que é mais importante, não houve nenhuma atribulação social; na verdade, nossa sociedade está ainda mais harmoniosa agora. Não há como negar que isso é tudo muito impressionante (KOONCHUNG, 2011, p. 36). 
Soma-se a essa contextualização geopolítica feita pelo protagonista do romance Velho Chen (um escritor que tenta superar seu bloqueio criativo) o fato de a trama ser mediada por um fio vermelho que conecta misteriosamente os eventos narrativos. O enigma central do enredo refere-se ao sumiço do mês de fevereiro de 2011, fato que mobiliza os personagens principais (Fang Caodi, Xiao Xi e Velho Chen ou Lao Chen) da narrativa a ingressarem em uma busca perigosa por respostas. Essas respostas estão associadas à amnésia coletiva, ao enigmático desaparecimento do segundo mês do ano e aos episódios históricos de repressão cometidos durante o regime comunista, tal como a Revolução Cultural $^{5}$ (1966-1976), referente à governança maoísta (1949-1976), e o Incidente de Tiananmen ${ }^{6}$ (1989), ocorrido no penúltimo ano da liderança reformista de Deng Xiaoping (1978-1990).

Esse esquecimento inconsciente que acomete a maioria dos chineses é resultado dos mecanismos arbitrários operados pelo Partido Comunista Chinês contra o povo, a classe trabalhadora, com o intuito de manter as rédeas do poder. Tal mistério, entretanto, é a ponta do novelo ligado à formação de memórias nacionais obscuras e manipuláveis/manipuladas por instituições estatais, que, neste trabalho, contribuem para analisar a formação identitária da China em sua história mais recente, isto é, posterior à conjuntura reformista, marcada pela abertura econômica ao capital estrangeiro realizada por Deng Xiaoping (1904-1997), sucessor do líder revolucionário e fundador da República Popular da China Mao Tsé-Tung (1893-1976).

Historicamente, essa transição política foi marcada pela inserção da China no mercado globalizado, uma vez que o “socialismo com características

\footnotetext{
${ }_{5}^{5}$ Para o diplomata brasileiro Mauricio Lyrio (2010), a Revolução Cultural foi um período marcado pelos seguintes aspectos: "o virtual fechamento por dez anos do ensino médio e universitário, a perseguição indiscriminada de professores e pesquisadores, a desvalorização da educação nos mais diversos níveis e a repressão a muitas formas de produção e manifestação cultural, reduzidas em boa medida a propaganda" (LYRIO, 2010, p. 55).

${ }^{6}$ Esse episódio histórico foi resultado de uma insatisfação coletiva referente, inicialmente, à morte de $\mathrm{Hu}$ Yaobangou, um dos líderes mais liberais e populares do PCC que ocupara o cargo de secretário-geral do Partido. Contudo, sua dispensa foi deflagrada dois anos antes do Incidente, por Deng Xiaoping. Em comemoração à memória dessa figura política controversa à esfera partidária, uma quantidade significativa de estudantes chineses passou a se reunir regularmente na Praça de Tiananmen durante o mês de maio. Esses encontros logo transformaram-se em manifestações democráticas gerando uma instabilidade política, com a qual os dirigentes comunistas não souberam lidar de forma diplomática. Fatalmente, em 4 junho de 1989, as tropas comunistas assassinaram aqueles militantes.
} 
chinesas" - termo cunhado pelo líder reformista Deng Xiaoping na década de 70 do século XX - oxigenou a economia e a sociedade, ambas anteriormente arruinadas pela gestão administrativa durante a primeira liderança do Partido Comunista, quando houve a execução improdutiva dos quatro programas de modernização maoísta: “Grande Salto para Frente” (1953-1957), “Campanha das Cem Flores" (1956), “Campanha Antidireitista” (1957) e "Revolução Cultural" (1966-1976). Essas medidas resultaram em um crescente período de turbulência, caracterizado "pelo anti-intelectualismo, pelo patrulhamento e pela miopia ideológica, [na iminência de] quase destruir o partido que Mao mesmo ajudara a criar" (LYRIO, 2010, p. 86).

No que tange ao "socialismo com características chinesas", Henry Kissinger (2005), diplomata estadunidense, em seu livro Ordem mundial, afirma que esse modelo econômico liberou a energia latente do povo chinês. $\mathrm{Na}$ visão do intelectual norte-americano, a China, em um período menor do que o de uma geração, "avançou a ponto de se tornar a segunda maior economia do mundo. Para acelerar ainda mais essa espetacular transformação, a China - ainda que possivelmente não por convicção ingressou nas instituições internacionais e aceitou as regras estabelecidas da ordem mundial" (KISSINGER, 2005, p. 226).

A falta de convicção da China em relação a sua inserção nas instituições internacionais e, consequentemente, ao cumprimento das regras estabelecidas (democraticamente) pela ordem mundial evidencia um dos principais pontos de tensão que fazem parte do enredo de Os anos de fartura, que questiona a qualidade democrática da China atual. Sobre esse tópico, Ping Chen, economista chinês e docente nas Universidades de Pequim e do Texas, alega que

há uma imagem disseminada de que o rápido desenvolvimento da China é realizado por um governo autoritário sem freios e contrapesos. Isso está longe da verdade. Historicamente, a China passou por inúmeras rebeliões e golpes de Estado liberados por militares, como no Império Romano. [...]. Há uma feroz competição aberta entre servidores públicos sobre inovação e não por poder pessoal.

$[\ldots]$

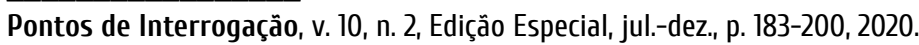


A democracia da China não é uma competição por palavras, mas uma competição por realizações. [...]. A legitimidade da China não reside no voto do eleitorado, mas no desempenho político e econômico. E este continuará a se aperfeiçoar e a inovar (CHEN, 2012, p. 202203).

Nessa linha de interpretação, a China contemporânea estabelece-se paradoxalmente como uma "democracia”, pois desconsidera a soberania popular e se legitima apenas no desempenho político e econômico, unilateralmente consolidado pelo Partido Comunista Chinês. Logo, essa noção de democracia, aliás como várias outras presentes no mundo "ocidental", expressa incoerência. Diferentemente de Ping Chen, seu compatriota Chan Koonchung, o autor de Os anos de fartura, apresenta um olhar crítico sobre o governo chinês, definindo-o como uma ditadura cujos lineamentos políticos, econômicos e culturais esculpem o "verdadeiro rosto da China".

Em uma entrevista concedida à BBC News, Chan Koonchung declarou: "Você sabe que na China, até que o Estado intervenha, até que o Estado tente impedi-lo de dar opiniões discordantes, você não pode ser considerado um dissidente" (BBC News, 2011, tradução de responsabilidade das autoras deste artigo). O então escritor torna-se partícipe desse "coro" opositor a partir da publicação de Os anos de fartura, em 2009. Portanto, após esse ato de coragem, ele se enxerga na condição agambeniana de ser contemporâneo, no campo literário, ao perceber o que para a grande maioria estaria oculto. Para Giorgio Agamben, “o contemporâneo é aquele que percebe o escuro do seu tempo como algo que lhe concerne e não cessa de interpelá-lo, algo que, mais do que toda luz, dirige-se direta e singularmente a ele. Contemporâneo é aquele que recebe em pleno rosto o facho de trevas que provém do tempo" (AGAMBEN, 2013, p. 64).

Inicialmente, o romance de Chan Koonchung, crítico ao Estado totalitário chinês, foi publicado apenas em Hong Kong e Taiwan. É importante informar que essas duas “ilhas rebeldes", em especial a segunda nação insular, não se encontram sob o jugo ideológico do Partido Comunista, embora sejam consideradas, por fatores históricos atinentes à política interna da China, pertencentes ao mesmo território. Em 2009, quando o Partido soube da 
existência de Os anos de fartura, os censores impediram a obra de circular na China continental. Em vista disso, "nenhuma editora chinesa do continente se dispôs a publicá-la" (BBC News, 2011, tradução de responsabilidade das autoras deste artigo).

Evidentemente, esse episódio repressivo vivenciado por Chan Koonchung configura-se como um caso real de censura em âmbito nacional. Apesar da falta de liberdade de expressão vigente, cópias clandestinas da referida obra foram difundidas, inclusive através da internet. Essa situação verídica exemplifica e aciona a metáfora apresentada no primeiro parágrafo deste artigo: Afinal, qual é "o verdadeiro rosto da China", na contemporaneidade? Posto isso, traça-se outra imagem literária, a fim de ampliar a anterior: Afinal, qual é, na contemporaneidade, o verdadeiro rosto da China por trás da máscara? Máscara essa que funciona, em uma perspectiva antidemocrática, como um aparato discursivo para esquecer e encobrir outros rostos, outras histórias, outras memórias, outras múltiplas memórias (ACHUGAR, 2006, p. 161).

\section{A máscara modelada pelo Partido Comunista Chinês (PCC)}

Nota-se, no desenrolar dos acontecimentos de Os anos de fartura, que o romance denuncia como disfarce o discurso nacionalista do PCC, na medida em que o aparelho do partido promoveria, nas palavras de Hugo Achugar (2006, p. 161), a "configuração de imagens, disfarces, relatos e processos que, ao mesmo tempo em que ocultam uma identidade, constroem outra." A respeito do papel da memória, o poeta, ensaísta e pesquisador uruguaio salienta:

a memória tem uma tarefa fixa que a vincula à tradição. No entanto, o acontecido nos últimos tempos não parece respaldar essa afirmação, essa distribuição de tarefas, segundo a qual a memória ficaria encarregada de preservar o relato oficial ou hegemônico, baseando-se no "esquecimento" voluntário, ou involuntário, dos poderosos. Pelo contrário, a memória, para um amplo setor da sociedade contemporânea, teria a responsabilidade de resgatar os esquecimentos a que 
haviam sido submetidos indivíduos, obras e fatos históricos (ACHUGAR, 2006, p. 141).

Ao analisar o objeto literário deste artigo, observa-se que a trama apresenta uma disputa em torno de memórias: de um lado, o PCC estabelecendo criteriosamente o que deve ou não ser lembrado em caráter “oficial”, uma vez que a China do ano de 2013 posiciona-se, no enredo, como uma potência econômica em ascensão, e, portanto, o esquecimento dos momentos mais traumáticos da história recente desse país é de suma importância para forjar uma "máscara" nacional, por meio da produção de imagens que jovialidade, alegria e prosperidade tanto no imaginário local quanto no global; por outro lado, o personagem principal Velho Chen e seus dois companheiros de uma amadora busca detetivesca, Fang Caodi e Xiao Xi ou Pequena Xi (por quem o protagonista nutre um amor antigo), não hesitam em solucionar o enigma que tece os eventos narrativos: descobrir por que o mês de fevereiro de 2011 sumiu e qual a razão de a população chinesa estar tão contente - com exceção desses três personagens, com suas vozes politicamente antagônicas ao Partido.

Velho Chen, Fang Caodi e Xiao Xi assumem a "responsabilidade de resgatar os esquecimentos a que haviam sido submetidos indivíduos, obras e fatos históricos", conforme as palavras supracitadas do crítico uruguaio. Entre esses três dissidentes, Fang Caodi é considerado a "pessoa ideal" para ir atrás do mês desaparecido, porque a

vida dele era uma pilha de destroços, e não havia como erguer uma casa com eles. Ele vivia aparecendo em horários estranhos em lugares estranhos como se tivesse evaporado um milhão de anos atrás para renascer bem quando você menos esperava. Talvez alguém como ele realmente consiga algo tão fora de moda na política quanto restaurar um mês desaparecido de volta ao lugar (KOONCHUNG, 2011, p. 25).

Em razão dessa tarefa quase irrealizável, Fang Caodi cria uma rota de investigação, passando pelo sul de Beijing (Pequim), Hong Kong e Macau, com o intuito de localizar evidências sobre aqueles 28 dias. Ao longo de dois anos, esses indícios relevantes foram achados apenas nos "lugares mais 
estranhos". Por exemplo, em uma pensão no sopé do Monte Huang, ele encontrou uma edição completa da revista financeira Caijing que relatava como a nova crise econômica no início daquele fevereiro atingiu a China; no Estúdio Cinematográfico Mundial de Hengdian, em Zhejiang, viu uma parte do Seminário da Ásia de Hong Kong que falava sobre como as pessoas começaram a estocar comida naquele ano; em um vilarejo miserável perto da Universidade de Wuhan, em Hubei, descobriu a metade de um antigo exemplar do Diário da Juventude Chinesa, publicado pela Liga Comunista da Juventude, no qual o principal artigo, "O Leviatã chegou", apresentava o filósofo político ocidental no século XVII, Thomas Hobbes, e sua concepção monstruosa do Estado. De acordo com o artigo, ao defrontar-se com uma escolha entre uma anarquia e uma ditadura, o povo sempre escolheria a última; outro artigo trazia uma respectiva sobre os fracassos do governo na apuração da morte de uma jovem, ocorrida durante os protestos de dez mil pessoas em Wan'an, na província de Guizhou, e supostamente encoberta pela polícia (KOONCHUNG, 2011, p. 88-89).

Condicionados estrategicamente ao acesso dificultoso, à invisibilidade e, consequentemente, ao esquecimento, esses documentos “desempoeirados" por Fang Caodi evidenciam alguns episódios e temáticas referentes à repressão e à censura, estabelecidos no breve curso do mês perdido e em passagens específicas do regime comunista. Não foram apenas esses raros fragmentos de memórias contrários ou críticos que desapareceram. De acordo com a experiência de Fang Caodi, o personagem denuncia que,

durante a Revolução Cultural e no início da reforma e da abertura, havia pouquíssimos livros, e todo mundo sabia que os fatos reais estavam sendo suprimidos. Hoje, existe um caleidoscópio de livros por toda a parte; a quantidade de títulos é vertiginosa, mas os fatos reais continuam sendo suprimidos. A única diferença é que as pessoas têm a ilusão de estar lendo o que têm vontade e escolhendo as próprias leituras.

Ao continuar a pesquisa, descobriu que não conseguia encontrar nada usando termos de busca como " 4 de junho de 1989', 'Incidente de Tiananmen' e assim por diante. O material que aparecia sobre a Revolução Cultural era 
terrível - um amontoado de besteiras nostálgicas escritas para os que haviam passado a adolescência ao sol de um passado glorioso. Os poucos artigos que discutiam a história da Revolução Cultural não passavam de versões oficiais devidamente censuradas (KOONCHUNG, 2011, p. 149).

O protagonista Lao Chen, aconselhado por seu antigo conhecido Fang Caodi, também consultou na internet (institucionalmente monitorada) os sites da Dangdang e da Amazon chinesa para tentar localizar as obras da famosa escritora Yang Jiang, uma testemunha da Revolução Cultural, porém não havia nenhuma entrada com esse nome. Além disso, ele pesquisou o dia 4 de junho de 1989 ou Incidente de Tiananmen e sobre o Falun Gong em 1999 e, conforme o esperado, não obteve sucesso. Além da procura por tais vestígios históricos, Velho Chen

descobriu que tampouco havia livros sobre a Campanha de Retificação de Yan-na, a Reforma Agrária, o Muro da Democracia, o Movimento de Cinco de Abril, a Campanha contra a Poluição Espiritual e a Campanha para a Repressão do Crime - não havia nenhum livro sobre esses assuntos tão discutidos nos anos 80 e 90 . Os únicos livros que apareciam nos resultados eram A China contemporânea e uma edição popular da Breve história da China - duas obras básicas sobre história chinesa moderna e contemporânea autorizadas pelo governo nos últimos dois anos (KOONCHUNG, 2011, p. 148-149).

Tendo em vista essa coleta memorialística feita clandestinamente por Fang Caodi e Lao Chen, infere-se que a imagem nacional da China enquanto uma nação harmônica e próspera deveria ser mantida a qualquer custo, melhor dizendo, em concordância com a única versão autorizada pelo Partido Comunista. Para isso, o traumático passado protagonizado pelo maoísmo tinha que ser reescrito ou, até mesmo, oportunamente apagado da história recentíssima desse país. Essa tentativa de apagamento ou reescrita da história ocorre de modo similar ao desaparecimento daqueles 28 dias na memória coletiva da maioria dos chineses. Contudo, Fang Caodi consegue extraordinariamente reunir evidências e recolar o mês desaparecido em seu devido lugar. Desse modo, o desvelamento do enigma central da narrativa 
procede, também, através das lembranças íntimas desse personagem que desempenha o papel investigativo principal, embora seu trabalho tenha sido somado aos de Lao Chen e Xiao Xi.

Fang Caodi, figura fundamental nessa retomada, atinge finalmente seu objetivo, revelando que:

foi no oitavo dia do primeiro mês lunar após o Festival da Primavera, quando as pessoas começaram a voltar para o trabalho, que a televisão, os jornais e a internet trouxeram a mesma notícia: a economia global havia entrado em um período de crise.

De repente todos sentiram a iminência de um desastre [...]. No início, todos amaldiçoaram os Estados Unidos pela inflação fora do controle e pela desvalorização de um terço sofrido pelo dólar, que levou os chineses a perderem uma soma vultuosa de reservas estrangeiras acumuladas com tanto esforço.

$[\ldots]$

No início todos temiam a inflação, então compraram de tudo, esvaziaram as prateleiras e acumularam os produtos em casa. Enquanto todos faziam a mesma coisa, a oferta de produtos era insuficiente para suprir a demanda, e nesse ponto as compras motivadas pelo desespero começaram em meio a confrontos abertos entre os compradores.

Quando a Televisão Central de Beijing noticiou o caos social ao redor do mundo, não apareceu ninguém para assegurar à população que os estoques de comida e artigos de uso diário eram suficientes para suprir a necessidade de todos, como em geral acontece.

Xiao Xi lembrou que naquela tarde havia telefonado para vários intelectuais e pessoas ligadas à mídia para ver se tinham alguma ideia sobre o que fazer ou se aceitariam participar de um encontro para discutir a situação. Todos estavam ocupados demais estocando comida e outros insumos e ninguém tinha disponibilidade para discutir um plano abrangente de resposta.

Durante aquela semana, no entanto, as pessoas sentiramse como se estivessem no Purgatório; o tempo passava com extrema lentidão, e no sétimo dia ninguém mais aguentava e todos estavam prestes a desmoronar. Como você pode imaginar, vários elementos criminosos estavam ávidos por fazer o pior, e assim a população 


\begin{abstract}
estava aterrorizada. Quase houve uma histeria em massa. A anarquia total parecia iminente - a guerra de todos contra todos a fim de proteger a vida e a propriedade. As pessoas tinham uma única esperança que a máquina estatal começasse a funcionar o mais rápido possível.

No oitavo dia, o décimo quinto do primeiro mês lunar, um pequeno destacamento do Exército de Libertação Popular entrou na vila e recebeu uma acolhida calorosa. Dois anos atrás, no décimo quinto dia do primeiro mês lunar, quando o Exército de Libertação Popular entrou em Beijing para restaurar a ordem, a população de Beijing foi às ruas dar as boas-vindas. Naquela tarde, a Secretaria de Segurança Pública, a polícia armada e o Exército de Libertação Popular emitiram um comunicado sobre o início da repressão (KOONCHUN, 2011, p. 202-205).
\end{abstract}

Esse panorama apresentado por Fang Caodi deslinda o processo de um golpe de Estado, orquestrado, junto a conglomerados midiáticos nacionais, pelo PCC. Portanto, a transformação de um perigo iminente em uma "grande oportunidade" para a (re)implantação de uma ditadura evidencia o planejamento realizado pela cúpula intelectualizada e golpista do Partido Comunista. A intenção política seria “convencer as pessoas de que o Partido é a única esperança em uma crise de grandes proporções, de que o partidoestado é o único poder grande o suficiente para concentrar [...] recursos e fazer coisas grandiosas" (KOONCHUNG, 2011, p. 233).

Ironicamente, "a época de ouro da China" ou "os anos de fartura" chegariam devido à oportuna situação internacional e ao "golpe de sorte", aliás, golpe de Estado no contexto interno do país ficcional, permitindo ao governo autoritário chinês aproveitar-se dessa conjuntura econômica e política para criar uma suposta ordem a partir de um caos diariamente noticiado. Além disso, o Partido Comunista pretendia solucionar os assuntos inacabados dos últimos trinta e poucos anos de reforma e abertura econômicas (KOONCHUNG, 2011, p. 224). Desse modo, a população chinesa aceitaria de bom grado o retorno de uma ditadura liderada, mais uma vez, pelo Partido-Estado, em prol da manutenção da estabilidade socioeconômica. Afinal, ninguém queria vivenciar outro cataclismo político e econômico, como aconteceu durante a Revolução Cultural. No enredo de $O s$ anos de fartura, 
esse era um dos principais fantasmas do passado a assombrar, no presente ficcional, a sociedade chinesa.

Além do "golpe de sorte", Fang Caodi, Lao Chen e Xiao Xi descobrem - depois de executarem o sequestro de um oficial nacional e extraírem informações confidenciais dele - que o governo chinês

construiu uma indústria química de ponta em Hebei, capaz de produzir metilenodioxidometanfetamina (MDMA), popularmente denominado ecstasy. Essa substância começou a ser adicionada principalmente a todos os reservatórios de água potável, ao leite, ao leite de soja, às bebidas gaseificadas, aos sucos de fruta, à água engarrafada, às cervejas e aos saquês. Salvo por algumas áreas isoladas, foram atingidos $99 \%$ da população urbana e mais de $70 \%$ da população rural. As quantidades consumidas eram tão pequenas que sequer apareciam em um exame de urina convencional. As pessoas nunca descobriram, e graças ao MDMA ficariam em um estado permanente de leve euforia. Esse era apenas um pequeno programa complementar em apoio ao projeto de reforma política "Plano de Ação para Alcançar a Prosperidade em meio à Crise" (KOONCHUNG, 2011, p. 271).

Esse "pequeno" e ardiloso programa, em apoio ao suposto projeto nacional "Plano de Ação para Alcançar a Prosperidade em meio à Crise", pode ser considerado como a cartada final que consolidou o golpe de Estado. Desse modo, a República Popular da China passaria a usar a máscara discursiva de uma nação aparentemente próspera e harmônica atuando no posto de protagonista sobre o palco da geopolítica, entre 2008 e 2013. Pois, enquanto o Ocidente (Estados Unidos e Europa) sentia os graves efeitos da crise global em 2008, o Estado chinês ascendia economicamente e erguia-se, endossado pela grande mídia, como um "Leviatã" desejável por seus habitantes passivos e dopados que passariam a coexistir ilusoriamente em um perene estado de felicidade.

Michel Foucault (2005), em seu livro Em defesa da sociedade, discorre sobre a imagem hobbesiana do Leviatã, analisando-a enquanto "um modelo de um homem artificial, a um só tempo autômato, fabricado e unitário igualmente, que envolveria todos os indivíduos reais, e cujo corpo 
seriam os cidadãos, mas cuja alma seria a soberania" (FOUCAULT, 2005, p. 40). O Poder seria, então, construído pela soberania jurídica e pela instituição do Estado, alimentando-se do fenômeno de dominação maciço e homogêneo, ou seja, da dominação "de um indivíduo sobre os outros, de um grupo sobre os outros e de uma classe sobre as outras" (FOUCAULT, 2005, p. 34).

Em Os anos de fartura, a coexistência letárgica, alegre e amável entre os chineses deu-se, além do fator psicoativo, pela seguinte razão: "Como têm medo da anarquia e do caos, todos estão dispostos a se curvar ante o poder do Leviatã. Afinal só o governo de um Leviatã pode garantir a vida e a propriedade de todos. Em suma, a única possibilidade é oferecer ao estado ou ao governo um monopólio sobre a violência generalizada" (KOONCHUNG, 2011, p. 233). À vista disso, o Partido-Estado, beneficiando-se dos reflexos da crise internacional, criou as condições necessárias para (re)instaurar uma ditatura a qualquer momento. É nessa ideia geral que se desenvolve a narrativa distópica criada por Chan Koonchung.

Observa-se, portanto, que a revelação do mistério central de Os anos de fartura traduz-se em um apelo indireto à memória democrática cuja função de seus enunciadores diversos corresponde ao dever de "contar a história como uma história múltipla e, por isso mesmo, contraditória” (ACHUGAR, 2006, p. 160). Dito de outro modo, nessa trajetória detetivesca concretizada por Fang Caodi, Xiao Xi e Lao Chen, consta o esforço dessas três vozes dissidentes - incluindo, extraliterariamente, a do autor Chan Koonchung - para desmascarar as intenções do governo autoritário chinês, pois este se coloca enquanto o único "possuidor de um patrimônio, de uma história digna de ser narrada” (ACHUGAR, 2006, p. 161).

\section{Máscaras em negociação}

Para Hugo Achugar, “a narrativa de uma memória democrática, implica reconhecer os múltiplos cenários da memória nacional. Implica, além disso, a história como negociação, a história como produto da conversação, um debate entre os múltiplos atores ou enunciadores da memória nacional" (2006, p. 162). É a partir desse pressuposto teórico que, do nosso ponto de vista, Chan Koonchung, ao escrever Os anos de fartura, pensa a nação chinesa. O 
autor, portanto, compreende criticamente a "histórica como negociação", possibilitando, por exemplo, ao trio investigativo (Fang Caodi, Xiao Xi e Lao Chen) vociferar contra o autoritarismo em curso. Muito embora Koonchung assuma uma perspectiva progressista em relação à identidade nacional da China, sabe-se que

a memória democrática, sobretudo quando, além disso, é memória nacional, enfrenta o desafio da seleção. E, junto com a seleção, enfrenta o desafio da construção de uma identidade. Identidade, imagem, ou disfarce, que postulem uma relativa unidade. Um certo esquecimento das diferenças, uma relativa generalização (ACHUGAR, 2006, p. 161).

Nesse sentido, a terceira metáfora "máscara(s) em negociação" (que dá título a esta seção) surge como a superação do "paradoxo do disfarce democrático", tendo em vista que a construção identitária feita democraticamente mantém em algum grau uma visão generalizante sobre a nação e o nacional. Não se pode escapar disso. Com o intuito de tentar solucionar essa questão, Achugar pontua a necessidade de existir "uma máscara sucessiva e reiteradamente negociada, discutida" (ACHUGAR, 2006, p. 162). Para isso, o uruguaio chama atenção sobre o seguinte ponto:

a negociação, ao mesmo tempo, implica a releitura, ou a análise da nação e do nacional, tanto por parte do setor acadêmico como dos intelectuais, ou ativistas vinculados aos sujeitos sociais tradicionais, assim como aos novos sujeitos. Implica, ao mesmo tempo, uma batalha pelo discurso e pela representação. Implica, de fato, uma batalha por ocupar a posição do que tem/possui a história, do que sabe e do que escolhe. Esse sujeito que sabe - ou se apresenta como sabendo - age construindo um relato; mas também, como já vimos, inventando, descobrindo as fontes (ACHUGAR, 2006, p. 162-163).

Como foi mencionado, o enredo de $O s$ anos de fartura ambienta a nação chinesa no ano de 2013, logo, em uma conjuntura pós-revolucionária, especulando literariamente sobre um futuro que a todo instante evoca um recente passado fantasmagórico a fim de confrontá-lo, negociá-lo e evitá-lo. 
Parafraseando uma declaração do filósofo brasileiro Vladimir Safatle (2018), dada em entrevista a Pública, percebe-se que Chan Koonchung tenta criar uma China que acerte suas contas com a história, revisitando espectros repressivos do período maoísta e relembrando acontecimentos fúnebres mais atuais, como o Massacre de Tiananmen em 1989.7 Esquecer e silenciar tais acontecimentos opressivos não são opções viáveis para o corajoso ou, dependendo da perspectiva ideológica, do traidor da pátria, Koonchung. Apesar disso, pode-se inferir que o escritor chinês, ao traçar o que ficcionalmente constrói como o "verdadeiro rosto" de seu país, também lida com o inevitável desafio da seleção, uma vez que, conforme as palavras de Lilia Moritz Schwarcz no prefácio de Comunidades imaginadas, "imaginar é selecionar e obliterar" (ANDERSON, 2006, p. 15).

Chan Koonchung apresenta criticamente uma China contemporânea que experiencia uma surpreendente ascensão econômica e tecnológica em nível global, mas que, todavia, ainda comete internamente censura ideológica e atos de repressão, sobretudo, no campo das políticas de controle social. Esse futuro especulado em Os anos de fartura joga luz sobre os vestígios de um passado autoritário que ainda impossibilitam a construção democrática de um tempo (mais) recente. Logo, essa narrativa distópica pretende alertar seus leitores, principalmente os chineses, em relação ao risco iminente do retorno ou da continuidade de uma ditadura no país. Além disso, percebe-se o movimento histórico pelo qual a China superou o fracasso da

7 Em sentido contrário à condenação da censura operada pelo PCC, Domenico Losurdo, ao analisar a famosa foto do jovem que enfrenta o tanque de guerra, vai censurar a omissão de toda a sequência dos fatos ocorridos durante a revolta estudantil e denunciar os interesses estrangeiros que estariam na retaguarda das manifestações, que também não teriam sido isentas de violência. Vejamos como ele confronta o uso da imagem desse incidente: "Mas, a esta altura se impõe a pergunta quiçá mais inquietante: quem manipula a verdade mais e mais profundamente é a censura chinesa ou a aparente inexistência de censura da qual se vangloria o Ocidente? No primeiro caso, sem dúvidas temos de lidar com uma mutilação da verdade: um pedaço dela foi excluído. No segundo caso, bem longe de ser excluído, esse pedaço, essa fotografia, resultado de um tríplice processo de seleção, é obsessivamente mostrado e exibido, e, no entanto, essa verdade é agora apenas um momento da mentira em seu conjunto. Pior, tal verdade é agora parte integrante não apenas da mentira, mas de uma mentira que visa a impossibilitar a reflexão e a argumentação racional e a fabricar, como uma espécie de reflexo condicionado, uma indignação manipulada e suscetível de ser operacionalizada com sórdidos propósitos. E já está em ação a primeira função bélica da sociedade do espetáculo (a demonização do inimigo ou do inimigo em potencial) - enquanto a segunda está à espreita - , a sua transformação em espetáculo da violência exercida em nome da causa humanitária dos direitos do homem" (LOSURDO, 2016, p. 166). Como se vê, a verdadeira face da China é percebida de modo diferente, a depender do ponto de vista em que se encontra o intérprete da realidade desse país. 
modernização maoísta, passando pelo frutífero socialismo singular de Deng Xiaoping, até chegar ao ano de 2013. Nesse momento mais atual, a China fictícia caracteriza-se por uma agenda econômica capitalista, gerida por um regime centralizador, no caso, pelo Partido Comunista Chinês, que assume a figura do Leviatã, ou seja, a realidade apresenta-se muito distante do sonho da sociedade sem Estado que constitui a base da utopia comunista. De modo geral, o romance distópico de Chan Koochung problematiza a difícil conciliação entre democracia e crescimento econômico. Sendo assim, a China na contemporaneidade ainda espelharia sem muita nitidez uma China do passado.

\section{Referências}

ACHUGAR, Hugo. Planetas sem boca: escritos efêmeros sobre arte, cultura e literatura. Trad. Lyslei Nascimento. Belo Horizonte: Editora UFMG, 2006, p. $151-167$.

AGAMBEN, Giorgio. O que é o contemporâneo. In: AGAMBEN, Giorgio, O que é o contemporâneo e outros ensaios. Trad. Vinícius Nicastro Honesko. Chapecó: Argos, 2013, p. 55-73.

ANDERSON, Benedict R. Comunidades imaginadas. reflexões sobre a origem e a difusão do nacionalismo. Trad. Denise Bottman. São Paulo: Companhia das Letras, 2008.

CHEN, Ping. Uma abordagem chinesa. In: PERREIRA, Luiz Carlos B (Org.). Depois da crise: a China no centro do mundo? Rio de Janeiro: FGV, 2012, p. 185211.

FOUCAULT, Michael. Aula de 14 de janeiro de 1976. In: FOUCAULT, Michael, Em defesa da sociedade. Trad. Maria Ermantina Galvão. São Paulo: Martin Fontes, 2005, p. 27-48.

HAW, Stephen G. História da China. Trad. Joana Estorninho de Almeida e Rita Graña. Lisboa: Tinta-da-china, Ltda., 2008.

KISSINGER, Henry. Multiplicidade da Ásia. In: KISSINGER, Henry. Ordem mundial. Trad. Claudio Figueiredo. Rio de Janeiro: Objetiva, 2005, p. 174 -235.

KOONCHUNG, Chan. Chan Koonchung's dystopian vision of China in 2013. $B B C$ News, 07 ago 2011. BBC News. Entrevista concedida a Stephanie Hegarty. 
Disponível em: https://www.bbc.com/news/world-asia-pacific14326050\#: :text=Amid\%20one\%20of\%20the\%20biggest, of\%20life\%20in\%20modern\%20Chin. Acesso em: 01 de out. 2020.

KOONCHUNG, Chan. Os anos de fartura: China 2013. Trad. Guilherme da Silva Braga. Porto Alegre: L\&PM, 2011.

LOSURDO, Domenico. A esquerda ausente: crise, sociedade do espetáculo, guerra. Trad. Maria Lucília Ruy. São Paulo: Fundação Maurício Grabois e Ed. Anita Garibaldi, 2016.

SAFATLE, Vladimir. Quando você não acerta suas contas com a história, a história te assombra. Pública, 09 nov. 2018. Disponível em: https://apublica.org/2018/10/quando-voce-nao-acerta-\%20suas-contas-coma-historia-a-historia-te-assombra/. Acesso em: 02 de out. 2020.

Recebido em 20 de novembro de 2020

Aceito em 15 de dezembro de 2020 